\title{
Administrative Culture in Iran: an Institutional Approach
}

Mahdi Moulaee Ghara ${ }^{1}$ Ph.D. Student, Organizational Behavior Management Institute for Management and Planning Studies, Tehran, Iran.

Firooz Raznahan ${ }^{2}$ Assistant Professor, Department of Management, Institute for Management and Planning Studies, Tehran, Iran, (Author Corresponding).

Seyed Mohammad Zahedi ${ }^{3}$ Emeritus Assistant Department of Management, Institute for Management and Planning Studies, Tehran, Iran.

Saeed Moeedfar ${ }^{4}$ Emeritus, Assistant Professor, Department of Social Sciences,University of Tehran, Iran.

\begin{abstract}
Administrative system is a fundamental basis for development and shows how a government approaches the running of the country. Administrative governance behavior shows the type of administrative culture which dominates the country. Administrative culture at its fundamental analytical level looks at the behavioral pattern embracing the country's administrative system. Taking into account the modern institutional approach, this article intends to define and evaluate the administrative culture as one of the three main components of Iranian administration system. This study used an outsider's perspective/ approach (ETIC) to administrative culture and evaluated nine indexes: institutional collectivism, uncertainty avoidance, future orientation, performance orientation, power distance, in-group collectivism, humane orientation, assertiveness, and gender egalitarianism. Using random sampling method, data was collected from 166 managers, experts, and scholars of management. Findings show that power distance and in-group collectivism are perceived at a higher level, while there is a vital need to improve and develop institutional collectivism, future orientation, performance orientation, uncertainty avoidance and assertiveness. Finally, based on the findings, recommendations are presented to managers and researchers.
\end{abstract}

Keywords: Administrative Culture, Administrative Culture Dimensions, Administrative System, Modern Institutional Theory, Administrative System Development.

1.m.molaie@imps.ac.ir

2. f.raznahan@imps.ac.ir 


\section{عنوان مقاله: سنجش فرهنگ ادارى ايران: با رويكردى} نهادى' سنجش فم:

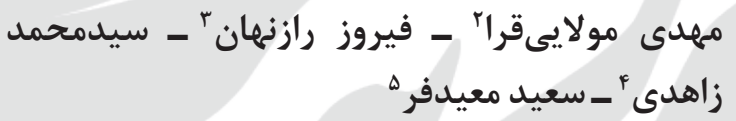

مقاله يزوهشى

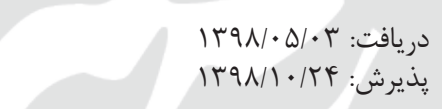

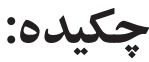

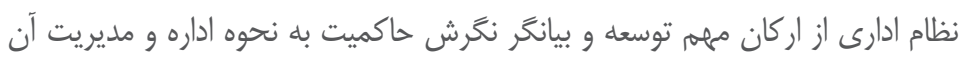

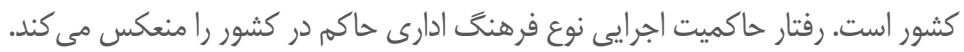

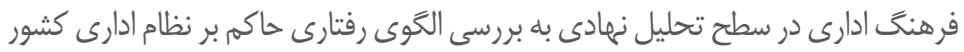

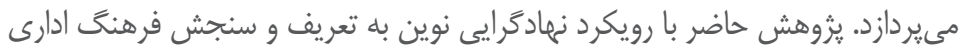

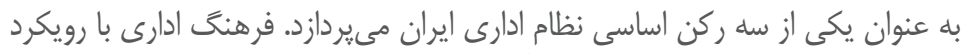

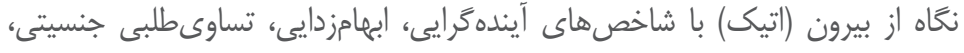

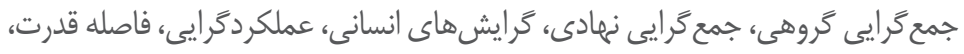

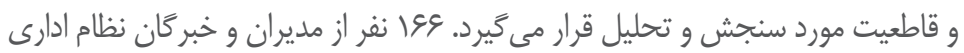

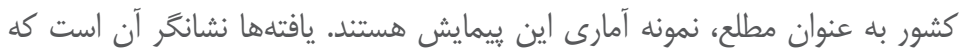

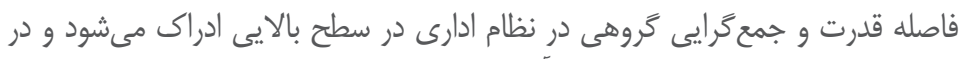

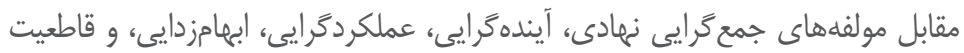

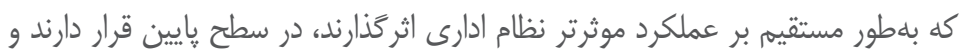

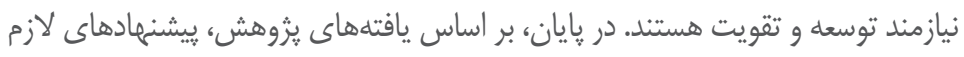

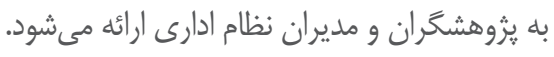

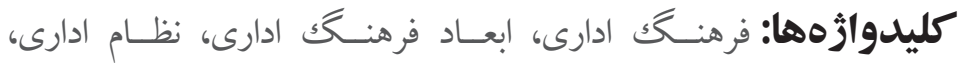

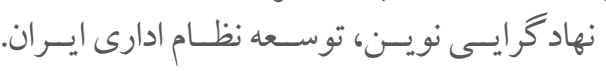

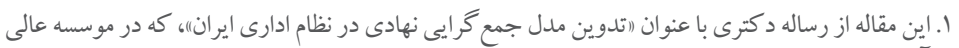

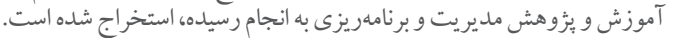

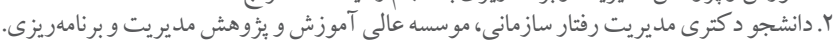
m.molaie@imps.ac.ir

ץ. استاديار گروه مديريت، مو سسه عالى آموزش و يُزوهش مديريت و برنامهريزى(نويسنده مسئول). raznahan@imps.ac.ir

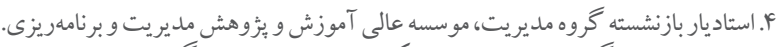

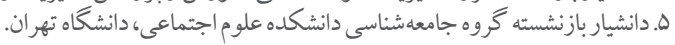




\section{مقام}

نظام ادارى از اركان مهم توسعه و بيانگًر نخَش حاكميت به نحوه اداره و مديريت كشور است.

"نقش آفرينى، اثرهاى تعيين كننده و استثنايى نهاد' ديوانسالارى و كاركرد آن در فرايند توسعه يايدار

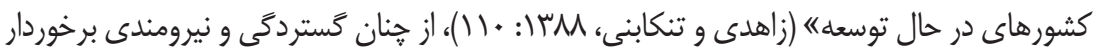
است كه يثوهشگًران و انديشمندان، توسعه كشورها را مشروط به وجود شرايطى از جمله برخوردارى

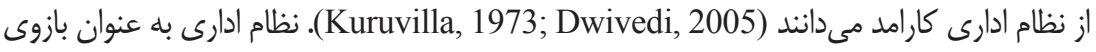

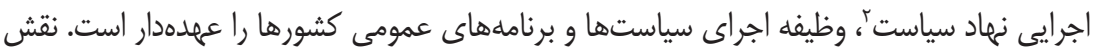
ممتاز و يخانه نهاد اداره به عنوان نرمافزار و نظام مديريتى مشترى نمادهاى مختلف جامعه در فراهم آوردن بستر و زمينه مشترك فعاليت نهادها، و همجنين تسهيل و ارتقاى اثربخشى تعاملات كاركردى نهادهاى مختلف در راستاى كليتى واحد به نام جامعه است. كاركردهاى ييشخفته، شناخت و توسعه نظامهاى ادارى را ضرورتى اجتنابنايذير مى كند. هرجند تا اواخر دهه • 19V بيشتر صاحبنظران

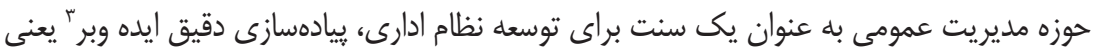
ديوانسالارى (بوروكراسى) را با تاكيد بر وجوه فنسالارانه و علمى نظام ادارى توصيه مىنمودند، اما بسيارى از يزوهشخران بهطور فزايندهاى به خار خوب مفهومى يِيجيدهترى از توسعه نظام ادارى تاكيد دارند كه مولفههايى همجِون فرهنگ، جغرافيا، جمعيتشناسى، فناورى، و اقتصاد را براى توسعه نظام ادارى اساسى قلمداد مى كنند، كه در اين ميان فرهنگ ادارى" از اهميت و جايگاه خاصى در طرحواره مفهومى آنها برخوردار است (Kuruvilla, 1973).

در دو دهل اخير، بلطور فزايندهاى روند جهانى اصلاحات و توسعه نظام ادارى در حال توسعه و تكامل است. اين امر با تلاش براى استقرار مديريت دولتى نوينه و حكمرانى خوب به به

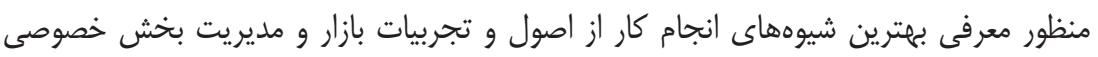
الرام مى گيرد. در نتيجة اين روند، فرهنَ ادارى بيشتر از هر زمان ديخًى مورد توجه است

1. Institution

2. Political Institution

3. Weber

4. Administrative Culture

5. New Public Management

6. Good Governance 
(Jamil et al., 2013; Jabbra \& Dwivedi, 2004)

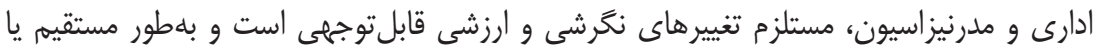
غيرمستقيم مفاهيم كليدى در فرهنگ ادارى را مخاطب قرار مىدهد (Dwivedi, 2005). با وجود اين، بلطور سنتى در تحليل نظام ادارى ايران، رويكرد ساختارى غالب است (فقيهى و همكاران،

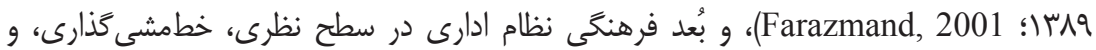
برنامهريزى مورد غفلت و حتى بىمهرى است. منطبق با رويكرد يِيشَفته، موضوع فرهنَ در

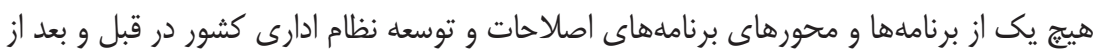

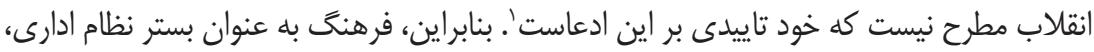

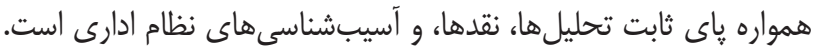
با توجه به نو بودن موضوع فرهنگ ادارى و محدوديتهاى ييشارو در زمينه يِيشينه تجربى، بهويثه در ارتباط با ابعاد، شاخصها، و نحوه سنجش آن، تلاش مى شود كه به با كاربست نظريه

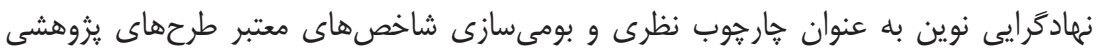
بينالمللى در سطح تحليل نهادى و نظام ادارى، ضمن فراهم آوردن زمينه معرفى فرهنگ ادادى

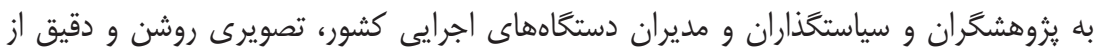
وضعيت مولفههاى فرهنح حاكم بر ديوانسالارى كشور و مدلولهاى نظرى و عملى آن ارئه ائه

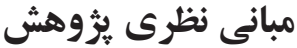

درك مفهوم فرهنگ ادارى از يكسو مستلزم شناخت مفهوم فرهنگ و از سوى ديخر، شناخت

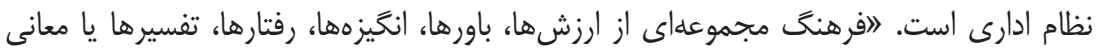

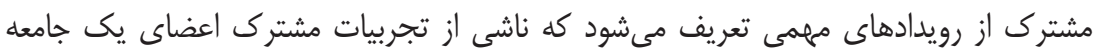

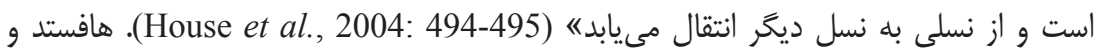

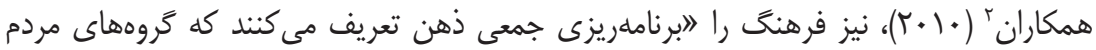

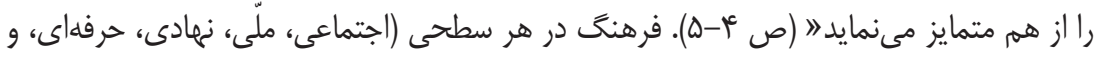

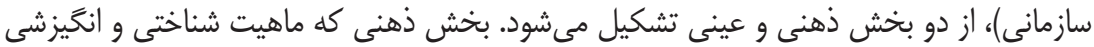

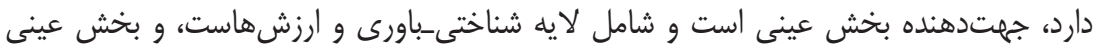

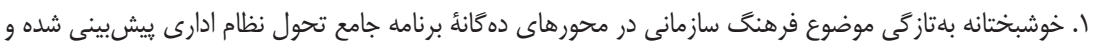

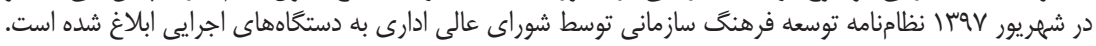
2. Hofstede et al. 
شامل الكوهاى رفتارى و مصنوعات و نمادهاست. بيشتر تعاريف مختلف از فرهنگ با تمركز بر

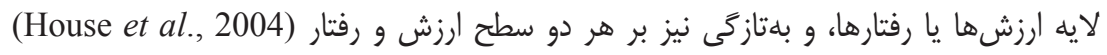

$$
\text { تاكيد مىشود. }
$$

نظام ادارى دومين عامل مهم شناخت مفهوم فرهنگ ادارى است. نظام ادارى يكى از نظامهاى

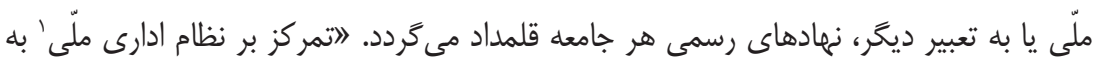

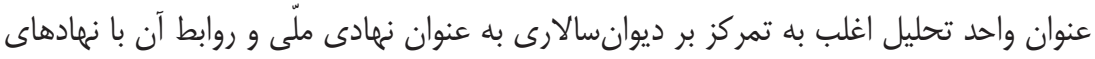

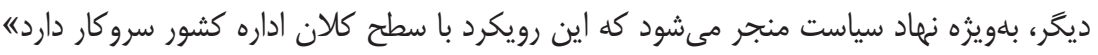

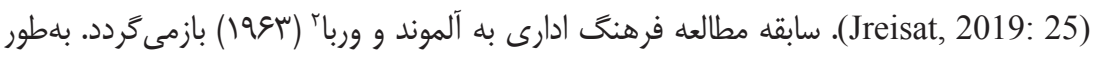

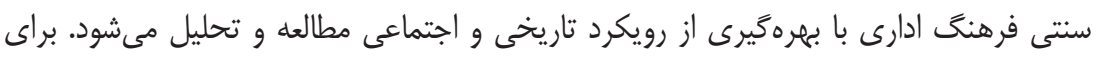

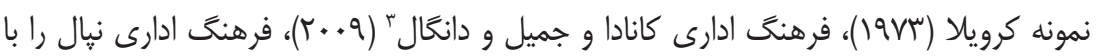

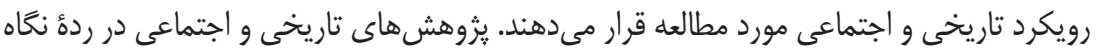

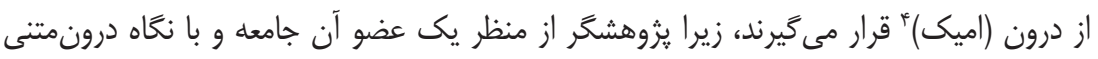

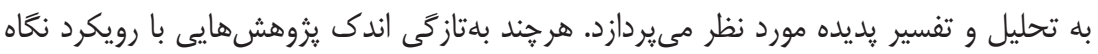

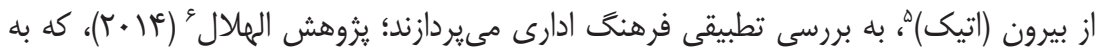

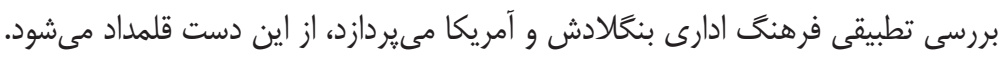

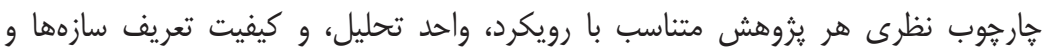

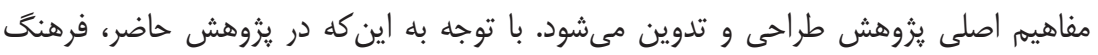

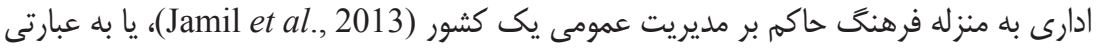

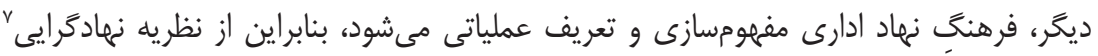

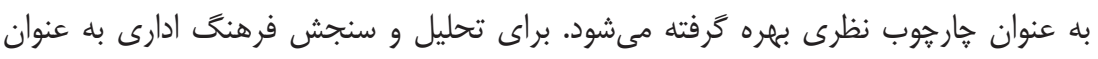

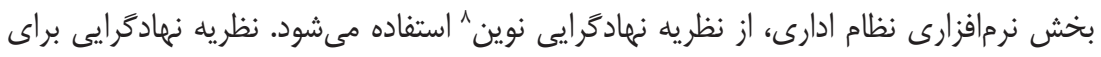

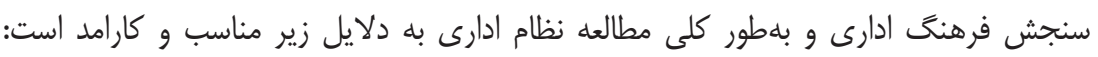

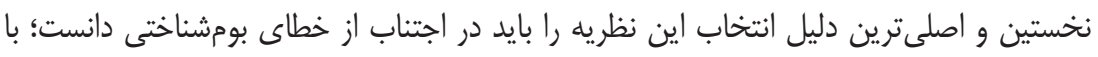

\section{National Administrative System}

2. Almond \& Verba

3. Jamil \& Dangal

4. Emic Approach

5. Etic Approach

6. Al-Helal

7. Institutional Theory

8. New Institutional Theory 
توجه به اين كه فرهنگ ادارى ركن نخست از اركان سهكَانه نهاد اداره است، بنابراين با انتخاب نظريه مناسب در سطح تحليل نهادى، از افتادن در ورطه خطاى بومشناختى كه اشاره به بكاركيرى نظريه(هاى) نامتناسب با واحد تحليل موضوع مورد بررسى است، اجتناب مى كَردد. دوم، بكار كَيرى

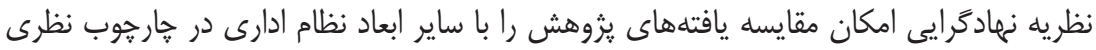

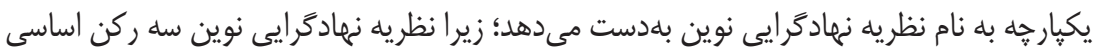

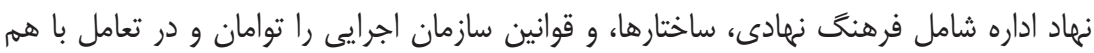

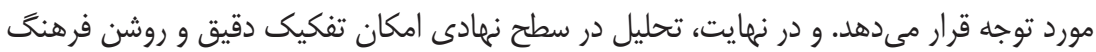

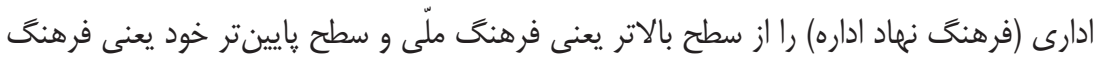
سازمانى فراهم مى كند و از ابهامها و سوءبرداشتها در اين خصوص مى كاهد.

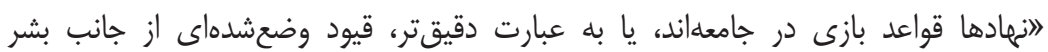

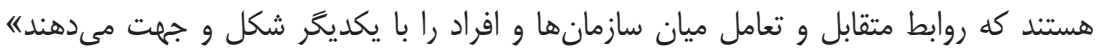

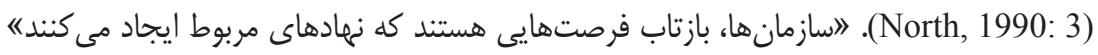

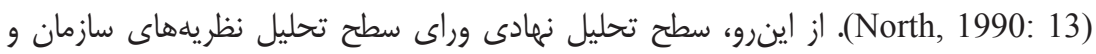

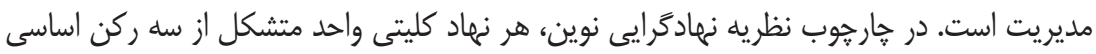

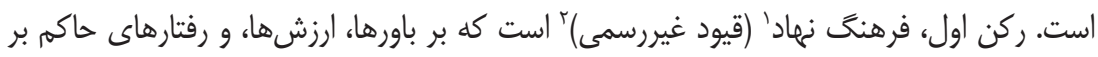

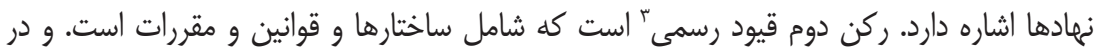

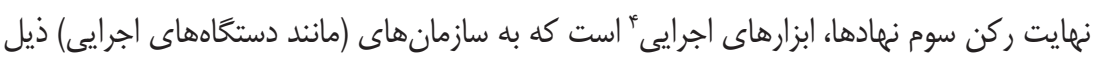

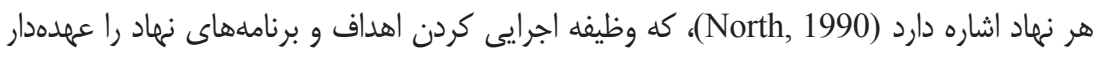

فرهنگ ادارى بخشى از فرهنَ اجتماعى و متاثر از فرهنگ سياسى است (Jamil et al., 2013).

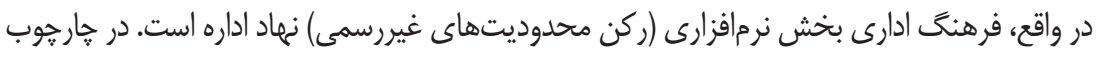

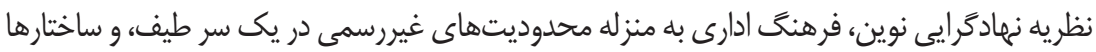

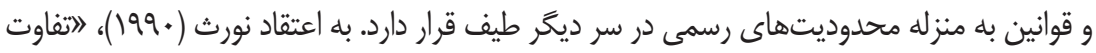
قيود غيررسمى و رسمى از حيث درجه است؛ كه يك سر طيف شامل رسوم و سنتهاست و سر ديخر آن قوانين و مقررات مكتوب است كه توسط نهادها ايجاد مى شود. اين طيف حر كر كتى بلندمدت و وناموزون

1. Institutional Culture

2. Informal Constraints

3. Formal Constraints

4. Enforcement 
از سنتها و رسوم غيرمدون به سوى قوانين مكتوب است كه با بيجِيده شدن جوامع، تخصصى شدن روزافزون، و تقسيم كار اين حركت يكسويه استه (ص عء؟). هيوم' استدلال مى كند هرجند كه

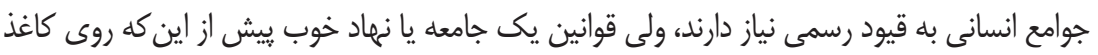
نوشته شود، بايد در قلب و ذهن شهروندان حك شود (Boettke \& Coyne, 2009). قيود غيررسمى منعكس كننده باورها، ارزشها، هنجارها، و سنتهاست؛ بنابراين خودهاجراست. همان طور كه در شكل (1) مشاهده مى شود، هنگامى كه قيود رسمى منعكس كننده قيود غير رسمى نباشند، اجراى قيود رسمى

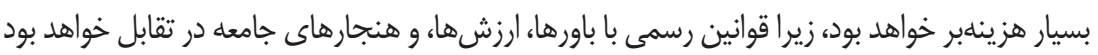

.(Boettke \& Coyne, 2009)

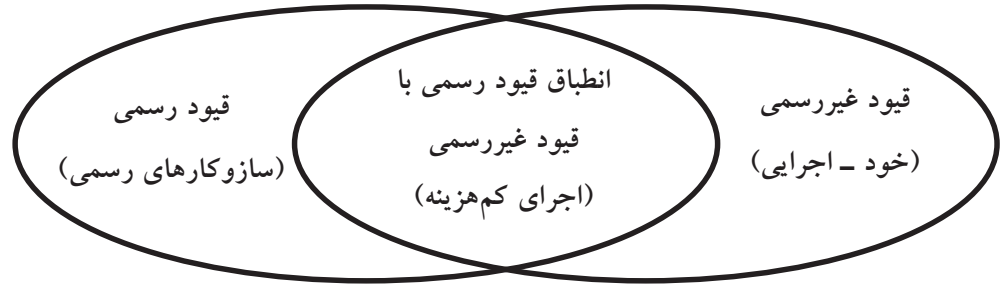

شكل 1: اثر تعامل بين قيود رسمى و غيررسمى (Sautet, 2005)

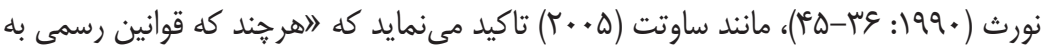

زندكَى و سيستمها نظم مىبخشند، با وجود اين در توسعهيافتهترين نظامها، قوانين رسمى بخش كوجى محدوديتهاى نظهمدهنده رفتار هستند؛ كاركرد متفاوت نهادها در مواجهه با قيود رسمى مشترى گَاه اهميت فراگير بودن قيود غيررسمى نهادها در نظهم بخشيدن به رفتار افراد است. اين دستاوردهاى متفاوت از قوانين رسمى در جوامع مختلف، جايخاه و اهميت قيود غيررسمى را اثبات مىنمايد... . موفقيت برنامههاى توسعه اقتصادى منوط به همخرايى قيود غيررسمى با قيود رسمى

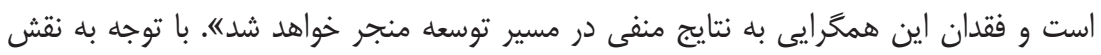
تعيين كننده قيود غيررسمى (در عملكرد و اثربخشى نهادها)، امروزه مطالعه قيود غير رسمى نهادها حوزهاى بنيادين، كاركردى، و مهم براى ثيزوهش است (Helmke \& Levitsky, 2004)، كه بلاصطالح فرهنَ نهادى ناميده مىشود. به دليل ارتباط نظام ادارى با نظام سياسى در سطح تحليل نهادى، تا حد زيادى ابداع مفهوم فرهنَ ادارى بايد به آلموند و وربا (سعه1) نسبت داده 
شود كه קارجوبى براى تحليل فرهنگ سياسى ارائه مىدهند (Kuruvilla, 1973). بنابراين،

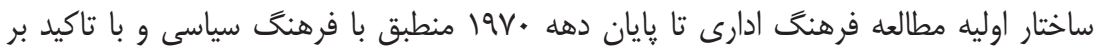

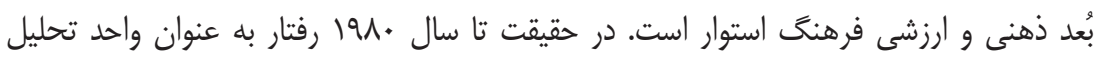

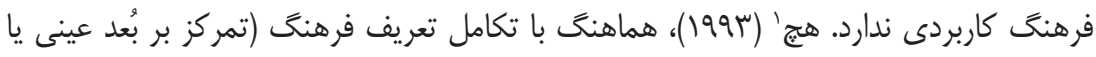

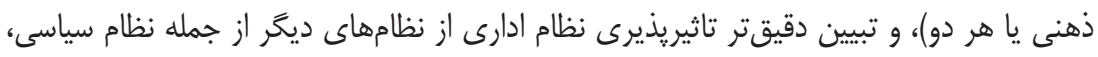
تعريف فرهنگ ادارى را توسعه مىدهد. گروهى از انديشمندان حوزه علوم سياسى و مديريت دولتى

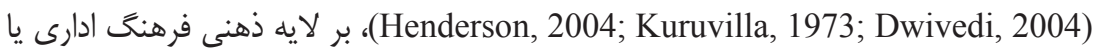
همان باورها، ارزشها، و نكَرشهاى مرتبط به شيوه انجام امور در نظام ادارى به عنوان جوهره

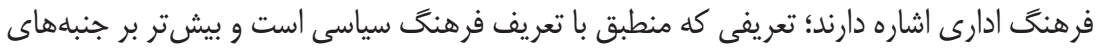

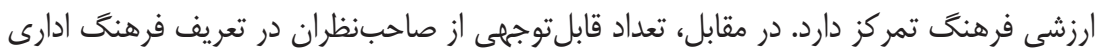

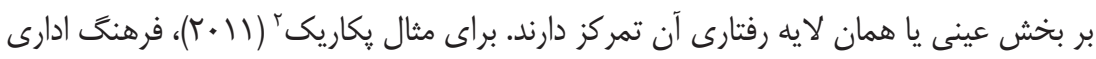

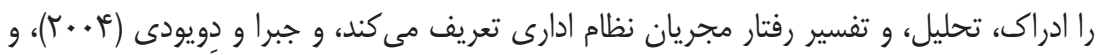

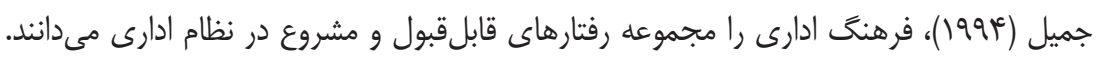
بر اساس تعاريف متداول امروزى، فرهنگ از مجموعه ارزشها، باورها، و هنجارهاى رهاى رفتارى

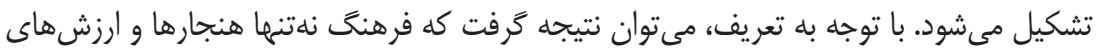
اجتماعى، بلكه رفتارها را تحت تاثير قرار مىدهد (Aoki et al., 2012).

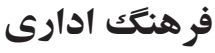

هرجند در يك دها اخير، مطالعه فرهنگ ادارى بلهور فزاينداى مورد توجه است، اما

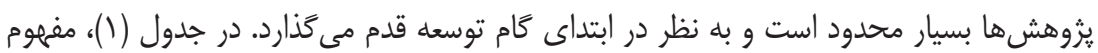

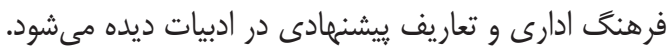

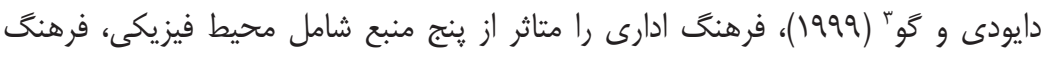

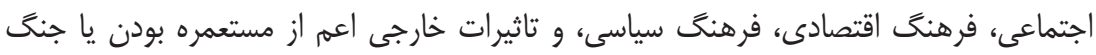

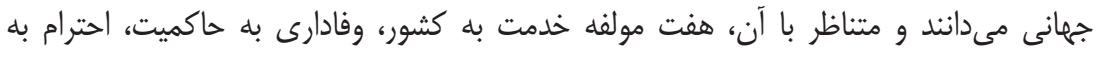

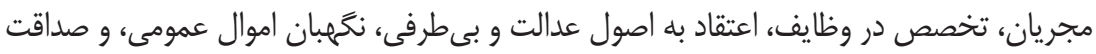

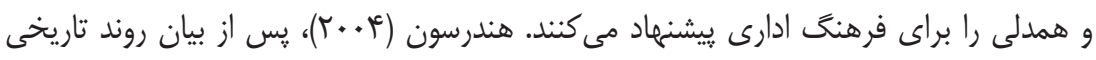

1. Hatch

2. Pečarić

3. Dwivedi \& Gow 
نظام ادارى آمريكا و تاثيريذيرى از كنشهاى سياسى، ابعاد فرهنگ ادارى را شامل بىطرفى،

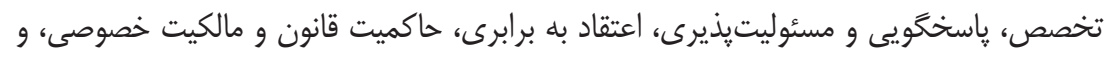

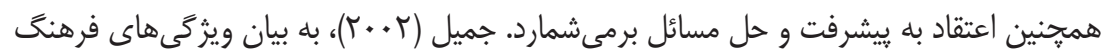
ادارى بنغكلادش مىيردازد. او به نقش عوامل داخلى نظام ادارى مانند فاصله قدرت، ابهامزدايى،

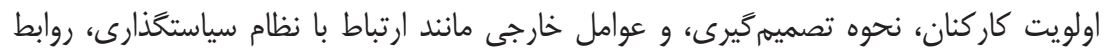

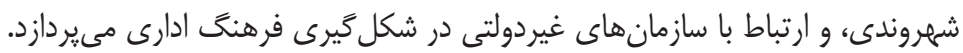

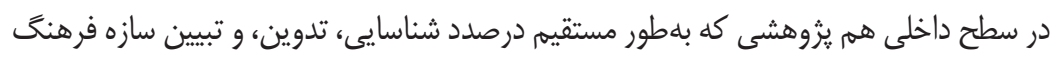

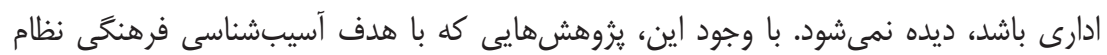

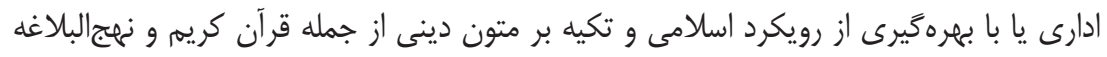

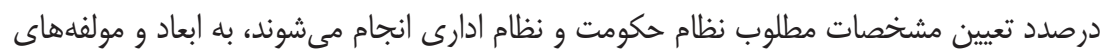
فرهنكى نظام ادارى مىيردازند. اين شاخصها كه با رويكرد نخاه از درون استخراج مى شوند،

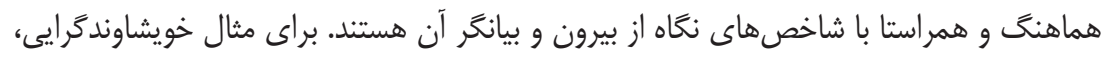

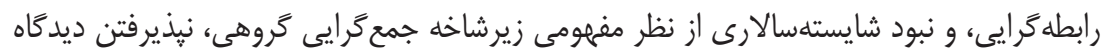

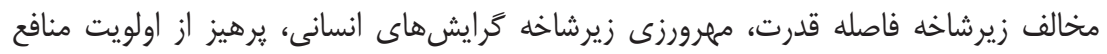

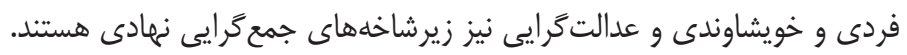

جدول ا: بيشينه بزؤششهاى فرهنك ادارى

\begin{tabular}{|c|c|}
\hline ابعاد مورد مطالعه & 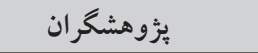 \\
\hline قانون گُ ايى، روابط غيرشخصى، تخصص گر ايى، شايسته سالارى. & كبر \\
\hline 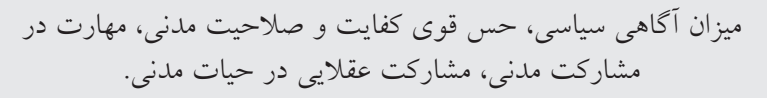 & 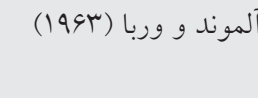 \\
\hline تخصص گرايى، خلاقيت، شايستهسالارى،بى طرفى جناحى، روابط غيرشخصى. & 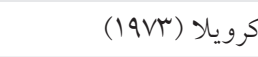 \\
\hline پِاسخكويى، پذيرش ديدكاه مخالف، كنترل و تعادل، استقلال يا & $(1994)^{\prime}{ }^{\prime}$ \\
\hline 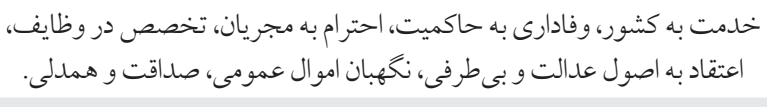 & 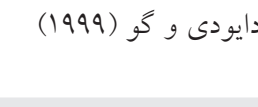 \\
\hline 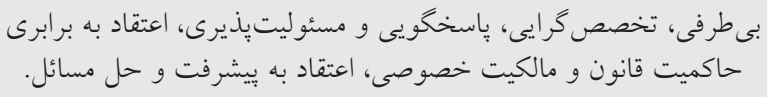 & هندرسون (Y. (Y. T) \\
\hline رابطه كرايى، نبود شايستهسالارى، منفعت طلبى فردى، بى عدالتى. & 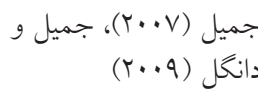 \\
\hline
\end{tabular}

1. Lam 
ادامه جدول ا: بيشينه يخوهش هاى فرهنك ادارى

\begin{tabular}{|c|c|}
\hline ابعاد مورد مطالعه & برُوهشكران \\
\hline فاصله قدرت، ابهامزدايى، اولويت كاركنان، نحوه تصميم گيرى. & جميل (Y..r) \\
\hline 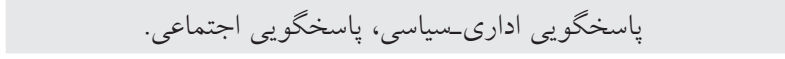 & جميل و حسين (T/ (T) \\
\hline 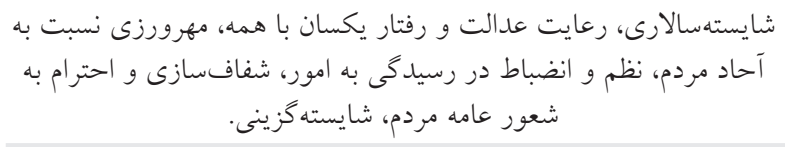 & يورعزت (ه (1) \\
\hline قانونمدارى در مقابل هارتىبازى، تعهديذيرى، نظارت بر كاركنان، & 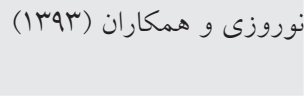 \\
\hline شايسته سالارى، پِاسخكويى، حفظ بيتالمال، حاكميت قانون، انتقاديذيرى & يورعزت (سوسا) \\
\hline 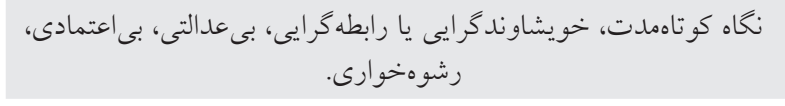 & كاتوزيان \\
\hline خويشاوندكرايى، نبود حاكميت قانون، نبود شايستهسالارى، تامين و & 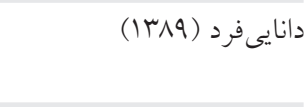 \\
\hline 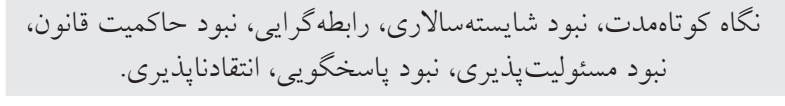 & ى و همكاران (ه (1+) \\
\hline 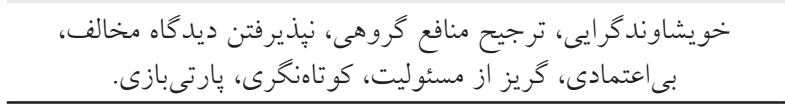 & فقيهى و همكاران (1) (1) \\
\hline
\end{tabular}

هرجند در يزوهشهاى داخلى جار جوب نظرى و مفهوم روشنى براى تدوين سازه فرهنَ ادارى نيست، با وجود اين، در يرداختن به نظام مديريتى و ادارى كشور در مولفههاى فرهنگى به صورت مستقيهم و غيرمستقيه يرداخته مىشود. براى نمونه آقاييروز (هوسا)، تاكيد مىنمايد كه اداره يا نظام در مديريت اسلامى به مجموعهاى از ارزشها، باورها، رفتارها، و ساختارهاى مورد

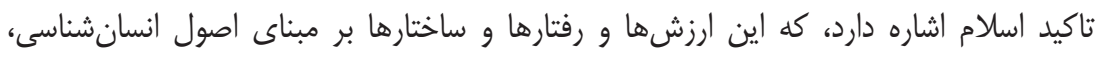
هستى شناسى، ارزش شناسى و معرفتشناسى برآمده از آموزهها و تعاليم اسلام است. براى مثال،

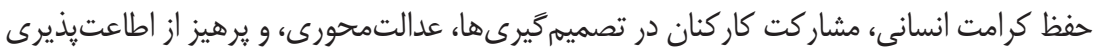
محض از تاثيرات انسانى شناسى برآمده از آموزها و تعاليم اسلام است. نوروزى و همكاران (سوسبا)، با تمركز بر تفسير الميزان بر تعهديذيرى، وفادارى، مسئوليتيذيرى، قانونگرايى، عدالتمحورى، بخشش، و ايثار به عنوان راهكارهاى كارامد مديريت اسلامى از منظر قرآن كريمم تاكيد مى كنند. همجنين يورعزت (هوس )، با تمركز بر نامه سه امام على(ع) به مالى اشتر شايستهسالارى، رعايت عدالت و رفتار يكسان با همه، مهرورزى نسبت به آحاد مردم، نظم و انضباط در رسيدگى به امور، 
شفافسازى و احترام به شعور عامه مردم، شايستهَزينى كاركنان، توجه به منافع عموم مردم، و يرهيز از اولويت منافع فردى و خويشاوندى را به عنوان مولفههاى شرايط اداره سالم نام مىبرد. همانطور كه در جدول (1) مشاهده مىشود، شاخصهاى استخراجشده به عنوان شاخصهاى فرهنَ ادارى، در ماهيت، تلفيقى از شاخصهاى رويكرد نخاه از درون و بيرون است. با توجه به هدف يزوهش حاضر و تمركز بر سنجش مولفههاى فرهنگ ادارى با استفاده از رويكرد اتيك يا

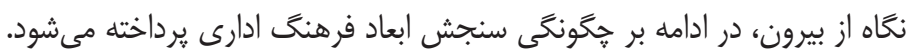

\section{سنجش فر هنگ ادارى}

يكى از بزرگترين هالشها در زمينه درى تكامل نهادها، سنجش فرهنَ نهادى است (Park, 2012; Randolph \& Rivero, 2017)

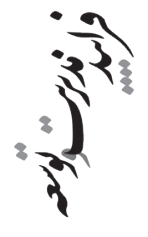

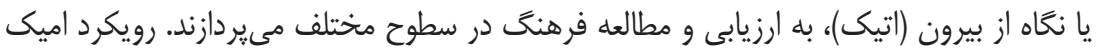
شناخت عميق مولفهها و عناصر يك فرهنگ با نخاه درونمتنى است و از منظر يك مشاهدهر

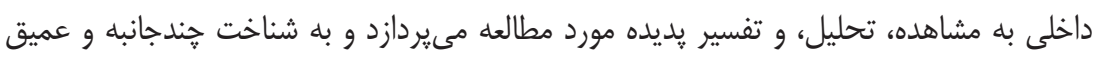
مىرسد؛ هرجند تعميهيذيرى اين يافتهها بسيار محدود است. در حالى كه در رويكرد نخاه از بيرون به فرهنگ، امكان شناخت و مطالعه شاخصهاى فرهنگ به صورت تطبيقى بلهدست مى آيد. يزروهشَران براى سنجش فرهنَ نهادى، از جمله فرهنَ ادارى، از شاخصهاى فرهنَى سطوح بالاتر يعنى سطح ملّى بهره مى كيرند (Garrido et al., 2014; Randolph \& Rivero, 2017).

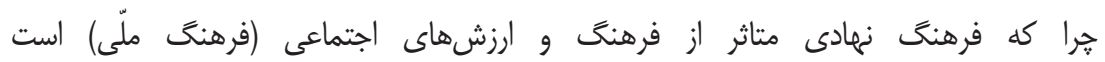

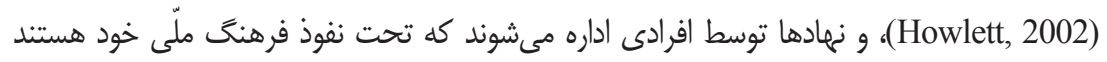

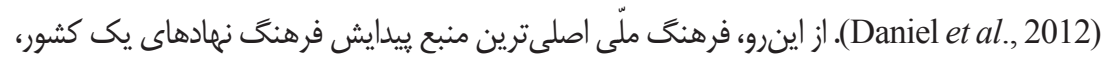
از قبيل فرهنگ ادارى و سياسى است (Garrido et al., 2014; Randolph \& Rivero, 2017). در سالهاى اخير، صاحبنظران با رويكرد نگاه از بيرون شاخصهاى بكارگرفتلهده رادر ييمايشهاى

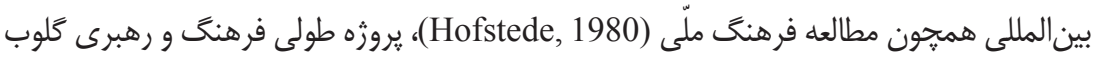

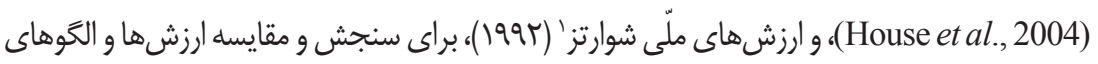
رفتارى افراد، گروهها، و سازمانهاو نهادها در جوامع و ملل مختلف، جايخزينهاى مناسبى براى سنجش فرهنَ نهبادى مى دانند (Garrido et al., 2014; Randolph \& Rivero, 2017; Park, 2012). در يزوهش حاضر، با استفاده از سنجههاى فرهنگى زيروزه طولى فرهنَ و رهبرى گلوب 
(House et al., 2004)، ابزار سنجش فرهنگ ادارى در سطح نهادى طراحى مىشود و سبِ

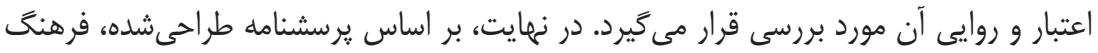
ادارى كشور سنجش، توصيف، و تبيين مى شود.

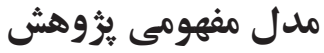

با توجه به ادبيات و ييشينه يزوهش، مدل مفهومى فرهنگ ادارى شامل ابعاد و مولفههاى

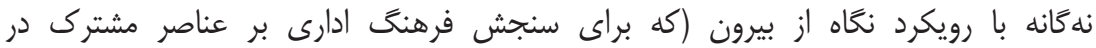

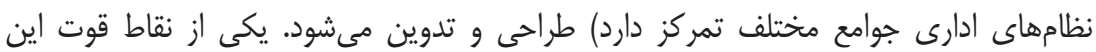
شاخصها، امكان مقايسه نهادهاى رسمى با هم و استفاده از مطالعات بينالمللى است كه

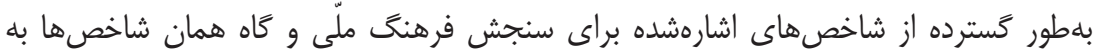
عنوان شاخص فرهنگ اقتصادى (Goldschmidt et al., 2006) مورد استفاده قرار مى كيرد.

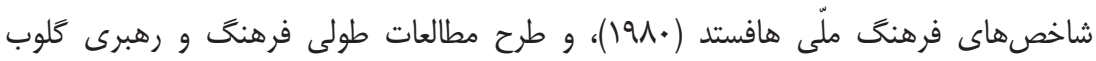
(House et al., 2004)، به دليل نفوذ و مقبوليت در محيطهاى دانشگاهى اقبال بيشترى دارند (Garrido et al., 2014; Randolph \& Rivero, 2017). بر همين اساس، شاخصهاى نهُانه فرهنگى طرح مطالعات طولى فرهنگ و رهبرى كلوب (House et al., 2004)، كه از جديدترين

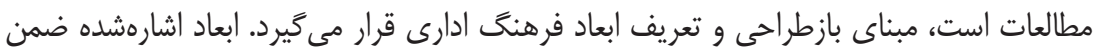
مقبوليت فراگير ميان بزوهشكَران، از قابليت لازم براى تبديل و تقليل به سطح سنجش در سطح نهادى نيز برخوردار هستند. همجنين، در سطح تحليل نهادى كه سطحى بين دو سطح بيشين

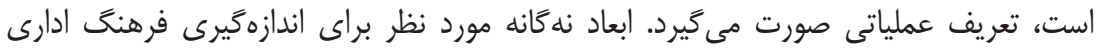

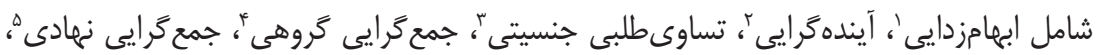

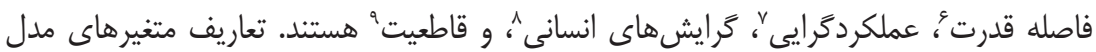

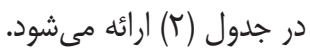

1. Uncertainty Avoidance

2. Future Orientation

3. Gender Egalitarianism

4. In-Group Collectivism

5. Institutional Collectivism

6. Power Distance

7. Performance Orientation

8. Humane Orientation

9. Assertiveness 


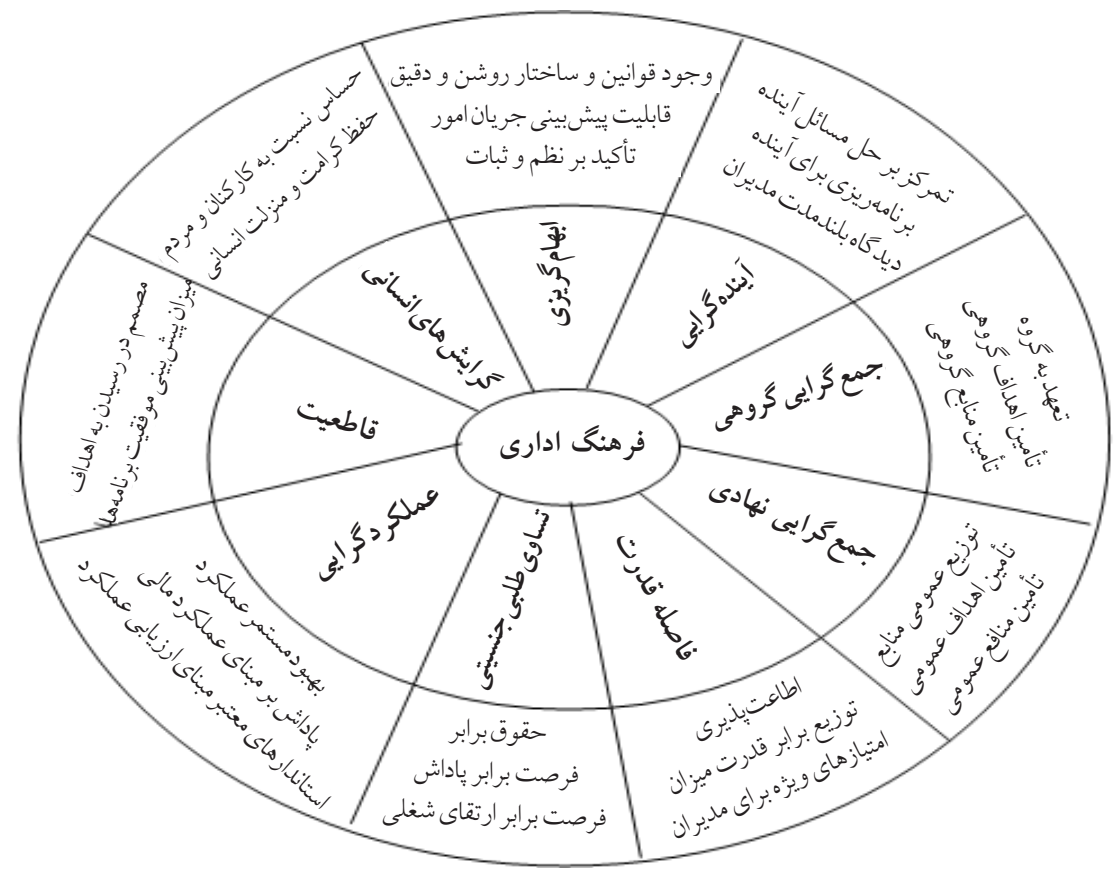

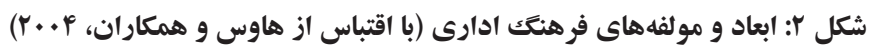

جدول r: تعريف ابعاد فرهنَك ادارى

\begin{tabular}{|c|c|}
\hline تعريف & مولفه \\
\hline 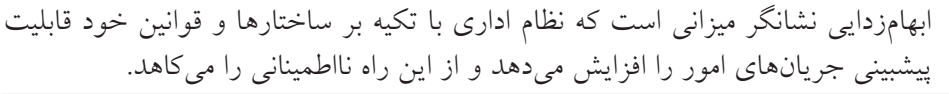 & بهامزدايى \\
\hline
\end{tabular}

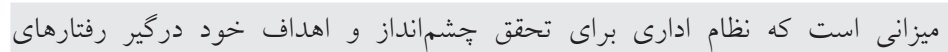

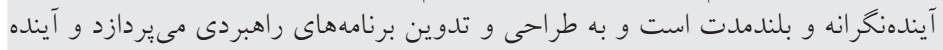

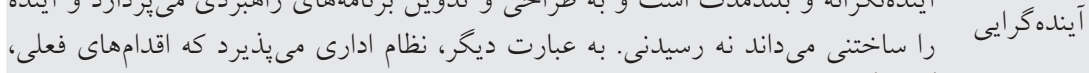

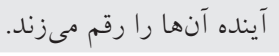

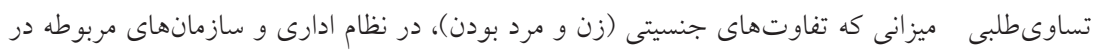

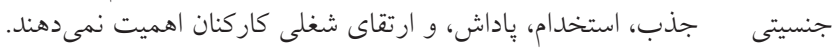

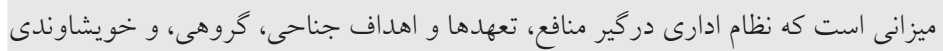

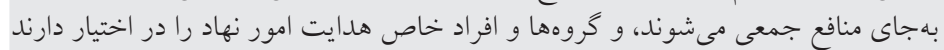

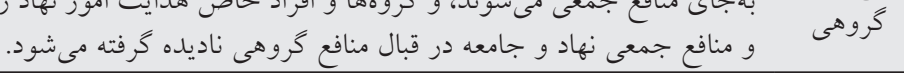




\begin{tabular}{|c|c|}
\hline تعريف & مولفه \\
\hline 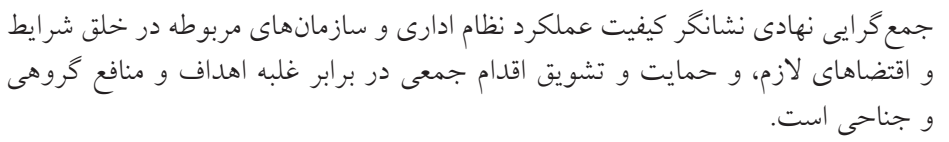 & جمع كرايى ن نهادى \\
\hline 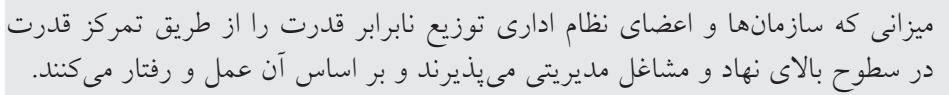 & فاصله قدرت \\
\hline 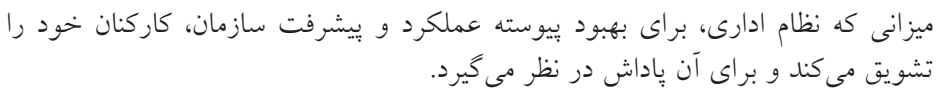 & عملكرد گرايى \\
\hline ميزانى كه افراد و سازمانهاى نظام ادارى در باور و كردار نسبت به ديخران حساس، مهربان، & كرايش هاى انسانى \\
\hline ميزانى كه نظام ادارى و سازمانهاى مربوطه در راستاى تحقق اهداف خود مصمم و قاطعانه & قاطعيت \\
\hline
\end{tabular}

\section{فرضيههاى يُوهش}

با توجه به مدل مفهومى و تعاريف عملياتى، فرضيههاى يزوهش به شرح زير طرح مىشوند:

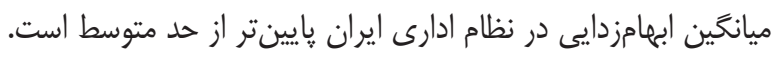

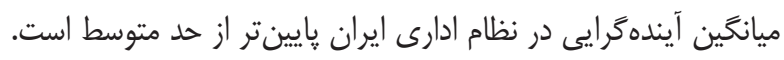
ميانگين تساوىطلبى جنسيتى در نظام ادارى ايران يإيينتر از حد متوسط است. ميانگين جمع گرايى گروهى در نظام ادارى ايران بالاتر از حد متوسط است.

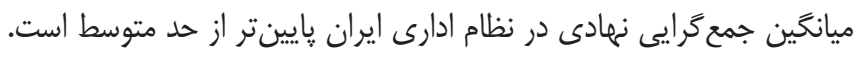

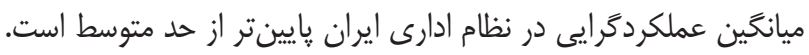
ميانگين فاصله قدرت در نظام ادارى ايران بالاتر از حد متوسط است. ميانگين قاطعيت در نظام ادارى ايران پايينتر از حد متوسط است. ميانگين گرايشهاى انسانى در نظام ادارى ايران يايينتر از حد متوسط است.

\section{روش}

در كلىترين سطح، مطالعه فرهنگ ادارى و نظام ادارى مىتواند با دو رويكرد نخاه از درون و نَاه از بيرون انجام شود. با توجه به اين كه امكان قضاوت و ارزيابى با شاخصهاى نكاه از درون 
محدود و ₹الشبرانخَيز است، بنابراين آَاهانه و هدفمند از رويكرد نگَاه از بيرون بهره گرفته مىشود. ابزار گردآورى دادهها، يرسشنامه تعديلشده يُوهش طولى فرهنَ و رهبرى كلوب (House et al., 2004) يرسشنامه فرهنَ اجتماعى و سازمانى يُوهش طولى كَلوب (با روش گروه كانونى)، و بازطراحى

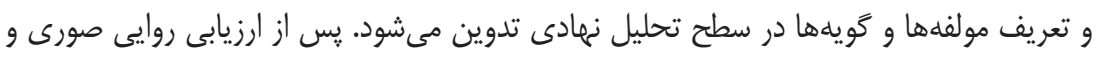

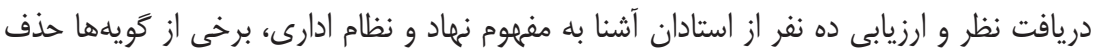

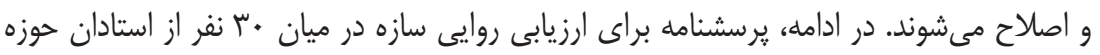
سازمان و مديريت دانشگاه تهران، تربيت مدرس، علامه طباطبايى، و شهيد بهشتى تهران توزيع

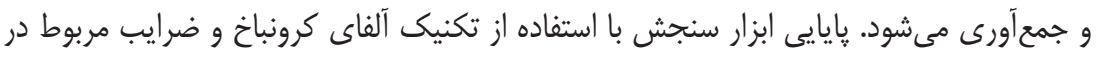

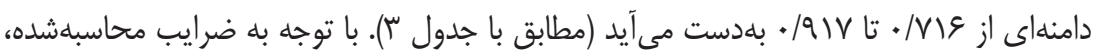

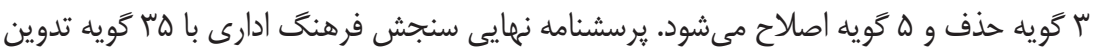

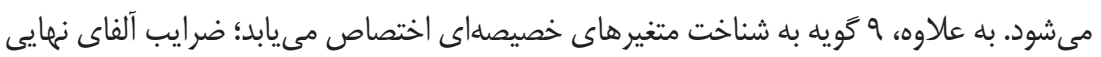
نسبت به ضرايب ييش آزمون بهبود مىيابد. جامعه آمارى اين يخوهش كليه مديران و كاركنان ارشد نظام ادارى كشور است كه در قالب دستخاههاى اجرايى در سه قوه مجريه، مقننه، و قضاييه وظيفه سياستخذارى، برنامهريزى، و اجراى ماى امور كشور را بر عهلده دارند. نمونه آمارى شامل عءا نفر از مديران عالى و ميانى، كارشناسان خبره در سطح سه قوه مجريه، مقننه، و قضاييه در سطح نظام ادارى كشور به همراه استادان دانشگاهى مانى حوزه سازمان و مديريت است كه به صورت تصادفى از جامعه در دسترس تعيين مىشوند. بدين ترتيب از هر سه قوه، تعدادى دستخاه اجرايى متناسب با كستره و اندازه دستخاههاى اشارهشده تعيين

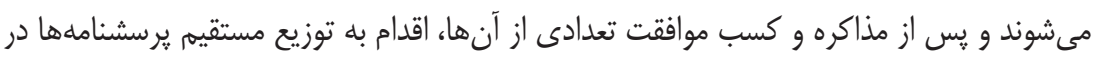

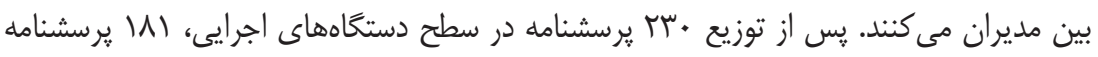

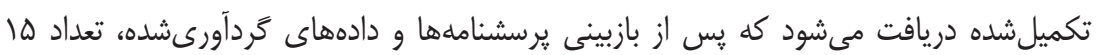

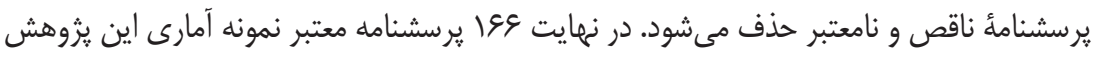
را تشكيل مىدهند.

\section{تجزيه وتحليل دادهها}

در اين ثيزوهش، براى توصيف دادهها و آزمون فرضيهها از دو نرمافزار 25 SPSS و -Smart بعره گرفته مىشود. براى آزمون فرضيهها روش مقايسه ميانخين تكنمونهاى انتخاب 
مىشود. آزمون t براى ارزيابى تفاوت بين ميانكين نمونه با ميانكَين جامعه يا تعيين حد ميانكَين

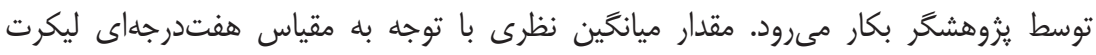

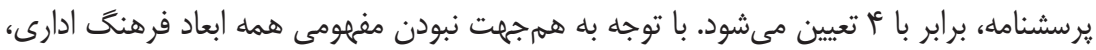
در مرحله تشريح و تبيين نتايج، طبق جدول (بّ)، همسوسازى جهت متغيرها اعمال مى شود.

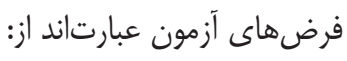

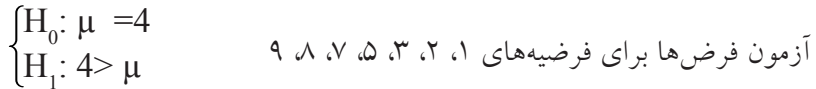

$$
\begin{aligned}
& \left\{\begin{array}{l}
\mathrm{H}_{0}: \mu=4 \\
\mathrm{H}_{1}: 4<\mu
\end{array} \quad\right. \text { آزمون فرضها براى فرضيه هاى }
\end{aligned}
$$

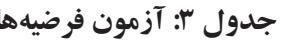

\begin{tabular}{|c|c|c|c|c|c|}
\hline نتيجه & $\mathbf{t}$ & ـارد ميانگين معيار & انحر اف استاند & ميانغين & متغير \\
\hline p & $-11 / 11 r$ & r & $1 / 4 \cdot 9$ & $Y / 9 \mathrm{~V}$ & ابهامزدايى \\
\hline 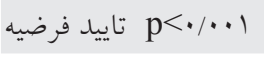 & -19/rNK & $r$ & $1 / 1 \Lambda F$ & $r / 99$ & آينده كرايى \\
\hline | تاييد فرضيه & אחתוצ & r & $\cdot / V I F$ & T/T & تساوىطلبى جنسيتى \\
\hline p إيد فرضيه & IV/GYT & r & $1 / \cdot \sqrt{ } q$ & Q/A & جمع گرايى گروهى \\
\hline 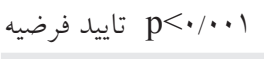 & $-9 / 7 V 1$ & r & I/TY & T/VY & جمع گر ايى نهادى \\
\hline 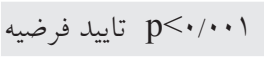 & KN/ANI & r & $\cdot / \wedge \subseteq \wedge$ & $9 / 14$ & فاصله قدرت \\
\hline 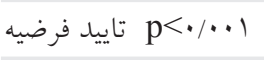 & $-Y I / \Lambda M V$ & r & $1 / 1 \wedge 4$ & $T / Y Q$ & عملكردگ ايى \\
\hline 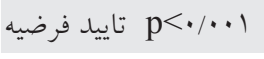 & $-11 / V D G$ & r & l/1AY & T/99 & كر ايشهاى انسانى \\
\hline تاييد فرضيه p< p</..l & $-19 / 994$ & r & $1 / 1 \mu 4$ & $r / \mu r$ & قاطعيت \\
\hline
\end{tabular}

بر اساس آمار هها و پارامترهاى بهدستآمده از تحليل دادهها، فرضيههاى يثوهش مورد ارزيابى

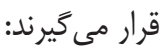
فرضيه ا: ميانكَين /بهامزدايي در نظام/دارى /يران بإيينتر /ز حد متوسط /ست.

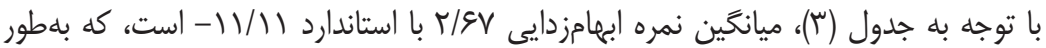

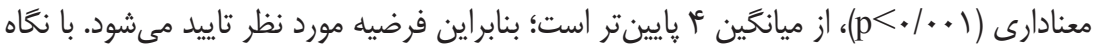
به ميانكَين محاسبهشده مىتوان اذعان نمود كه ميزان ابهامزدايى نظام ادارى ايران پإيين است.

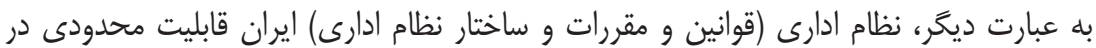




\section{ييشيينى جريانهاى امور و در نتيجه كاهش ميزان نالطمينانى دارد.

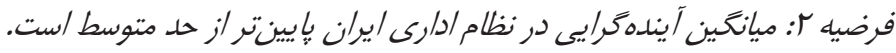

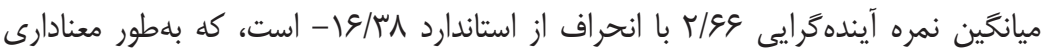

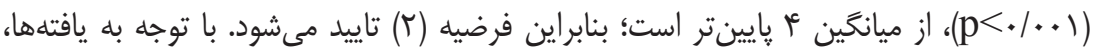

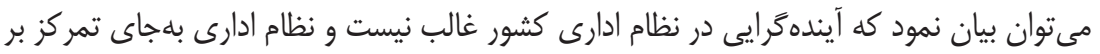

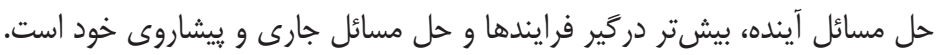

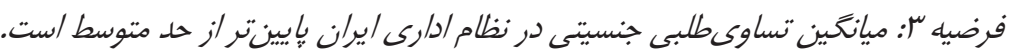

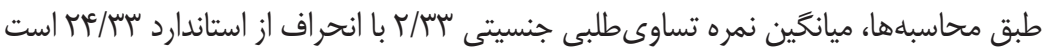

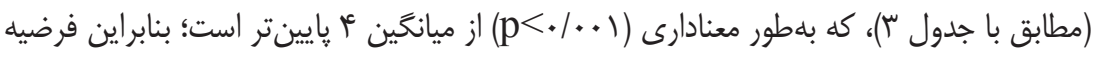

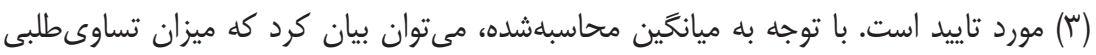

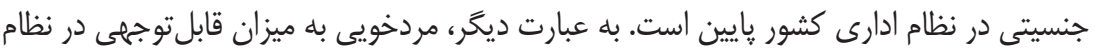

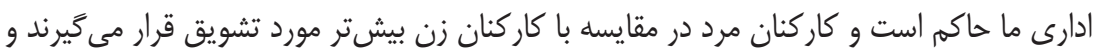
از فرصت بيشترى براى تصدى سِمتهاى بالاتر برخوردارند.

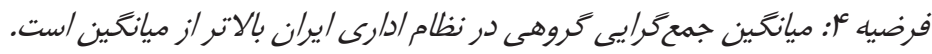

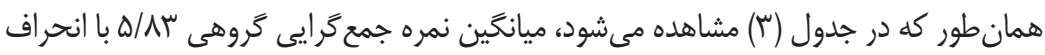

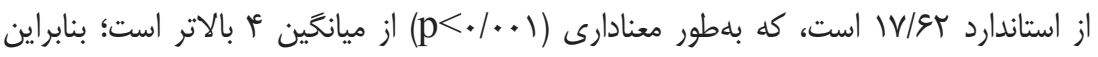
فرضيه (أ) مورد تاييد است. جمع كرايى كروهى ميزانى است كه نظام ادارى دركَير منافع، تعهدها

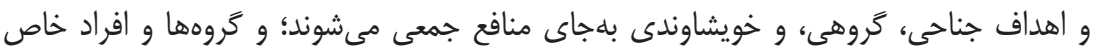

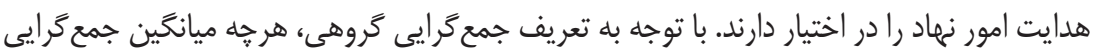

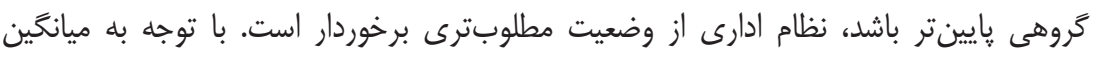

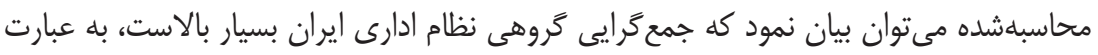

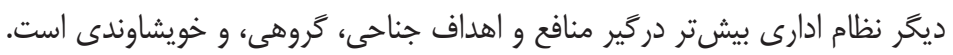

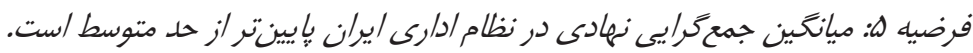

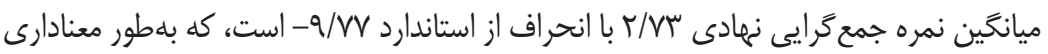

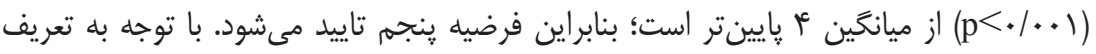

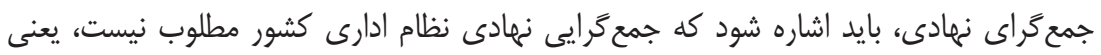
تخصيص منابع و خلق فرصتهاى نظام ادارى همراستا با اهداف و منافع عمومى نيست. از اينرو، نظام ادارى توانيى توسعه جمع كرايى نهادى را ندارد. 
فرضيه ك: ميانكين فاصله قدرت در نظام /دارى /يران بالاتر /ز حد متوسط /ست.

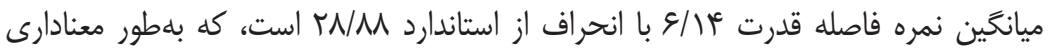

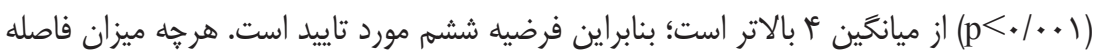
قدرت در نظام ادارى يايينتر باشد، نشان از مطلوبيت فاصله قدرت در نظام ادارى كشور است.

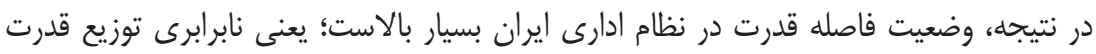

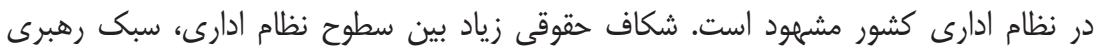

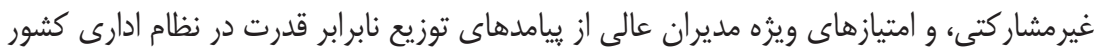

فرضيه V: ميانكين عملكردكرايی در نظام /دارى /يران بإبينتر /ز حد متوسط /ست.

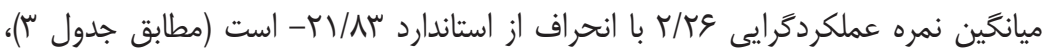

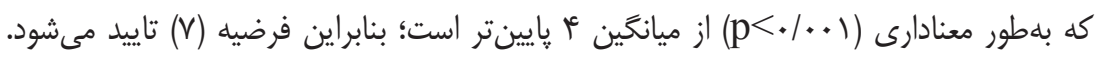

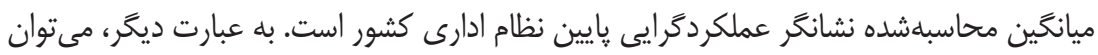

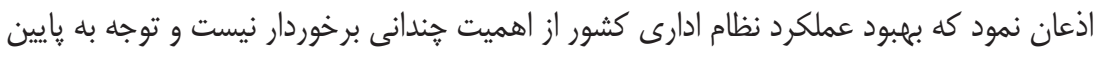

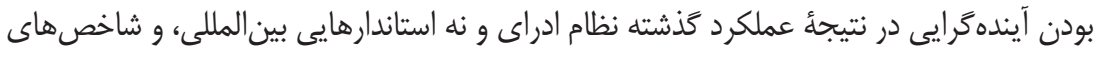

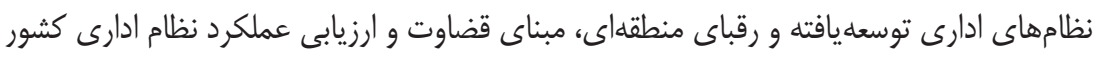

فرضيه 1: ميانكَين قاطعيت در نظام ادارى /يران بإيينتر /ز حد متوسط /ست.

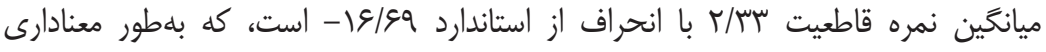

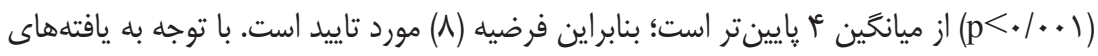

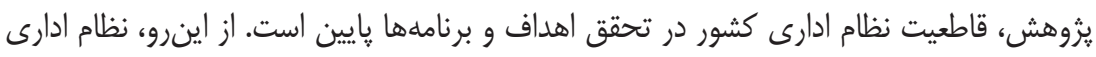

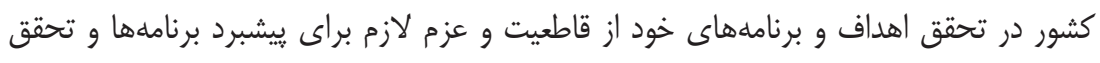
اهداف برخوردار نيست.

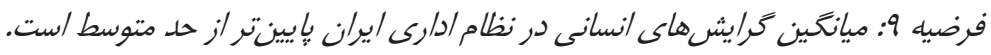

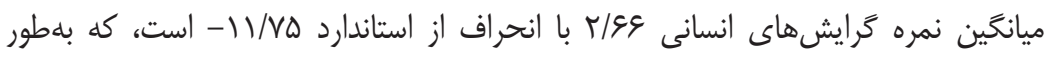

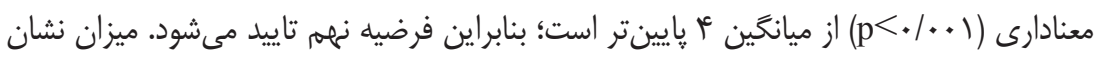

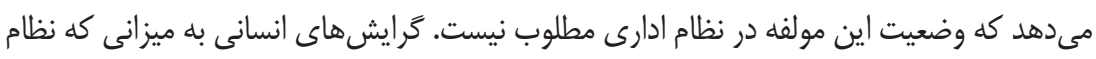

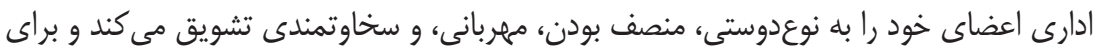

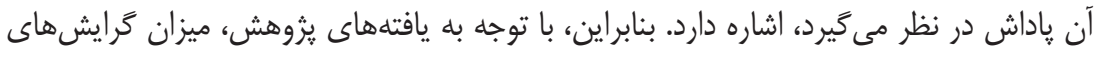


نظام ادارى كشور پايينتر از حد مورد انتظار است. اين در حالى است كه اصولاً در جامعه ما بر اساس يثوهشها، كَرايش انسانى در سطح ملّى بالاى متوسط است.

\section{بحث و نتيجه كيرى}

رفتار حاكميت اجر ايى منعس كننده نوع فرهنگ ادارى حاكم در يك كشور است، بنابراين كل

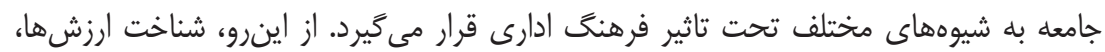

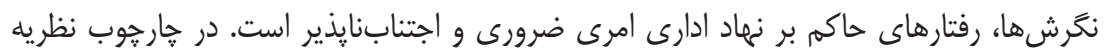

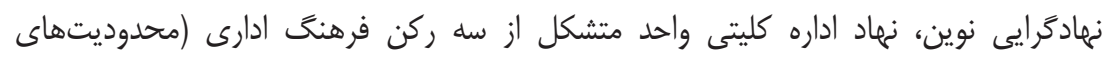

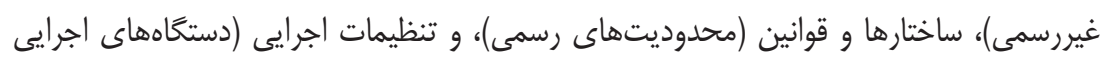

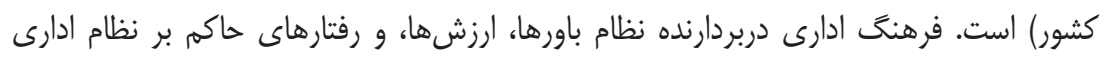

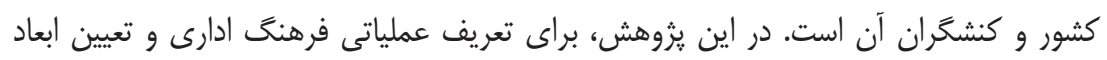

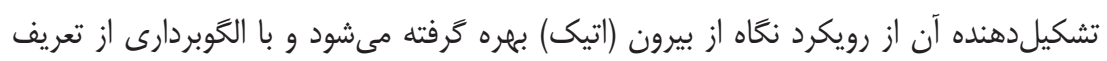

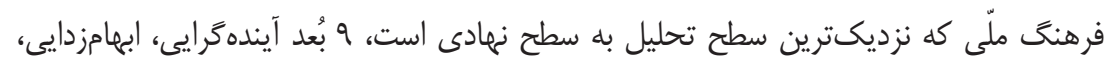

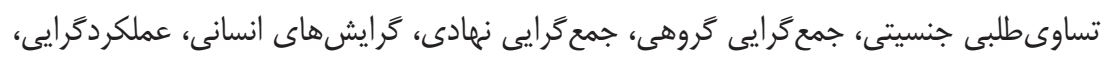

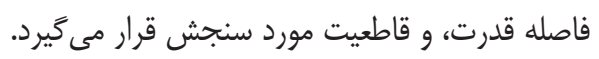

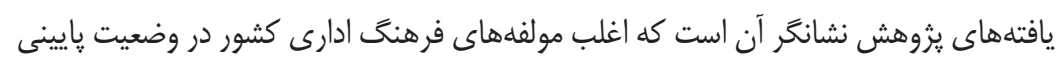

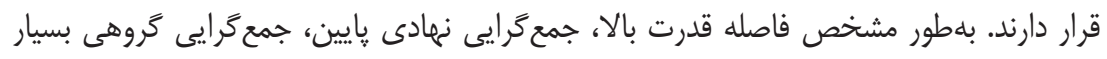

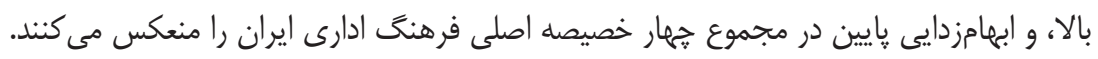

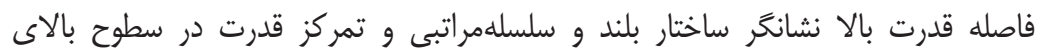

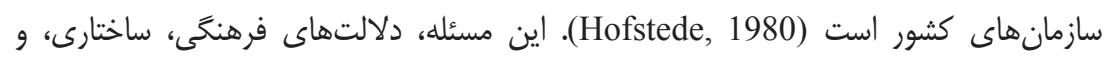

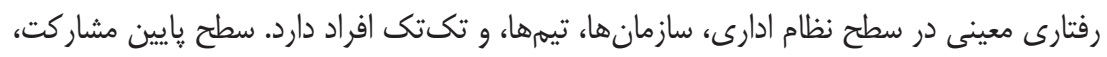

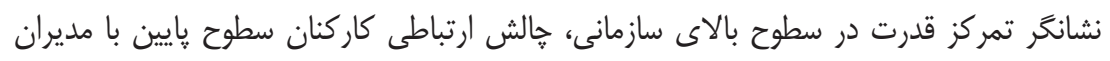

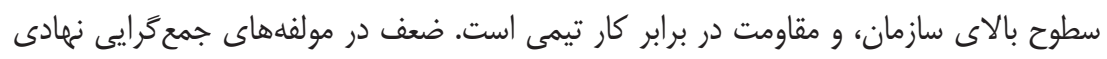

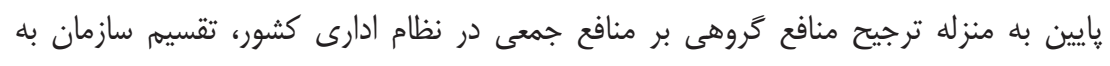

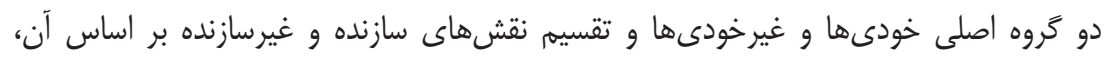

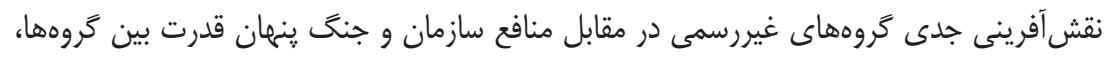

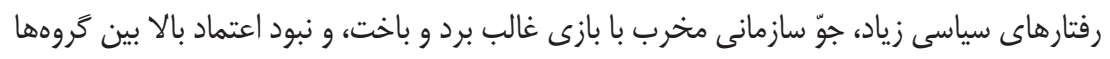

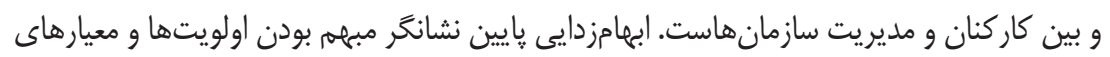


تصميمَّيرى در سطح سازمانهاى نظام ادارى، ضعف در ساختارها و رويههاى استاندارد عملياتى،

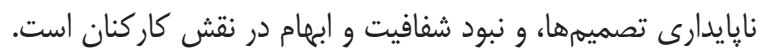

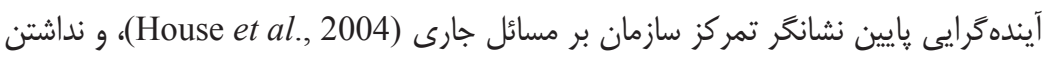
جشم|ندازى روشن و واقعى است. تصميمهاى سازمان متمركز بر مديريت مسائل جارى است و اغلب مديريت سازمان به صورت انفعالى درصدد حفظ وضعيت موجود سازمان است. مولفه عملكردگرايى يايين حكايت از كماهميت بودن كسب نتايج و تحقق اهداف واقعى سازمان است؛ در هنين وضعيتى با يادگيرى و نوآورى سازمانى به صورت شعارى برخورد مىشود و در عمل تشويق و ترغيب نمى شود. بهطور معمول، مبناى ارزيابى عملكرد جارى سازمان مقايسه با عملكرد سال كذنشته است و شاخصهاى ارزيابى عملكرد كيفى و منعطف انتخاب و تعريف مىشوند؛ ساعت

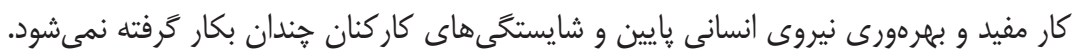

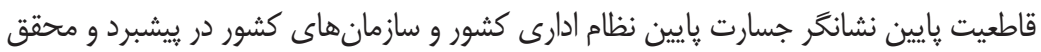

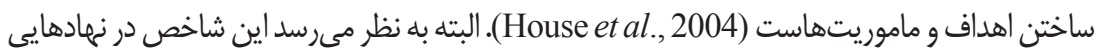
همجِون نهاد امنيت، دفاع، و علم و فناورى بلمراتب از نظام ادارى كشور بالاتر است. ترايشهاى

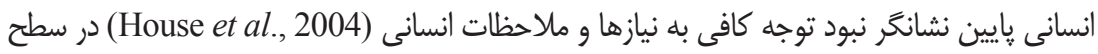

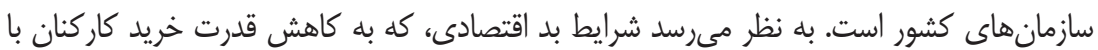
درآمدهاى ثابت منجر مىشود، و همجنين امنيت شغلى بخش قابلتوجهى از كار كنان كه داراى طيف

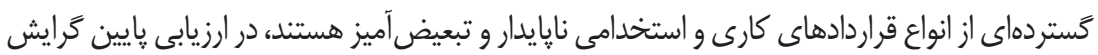
انسانى نظام ادراى موثرند. تساوى طلبى جنسيتى نشانكر سطح بلهنست يإيين تساوى طلبى جنسيتى با

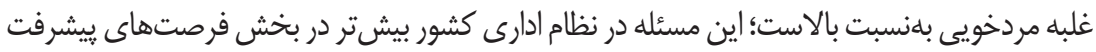
عمودى در سازمان و مزاياى دريافتى كاركنان است، زيرا بلطور معمول حقوق كاركنان زن و مرد بر بر برد

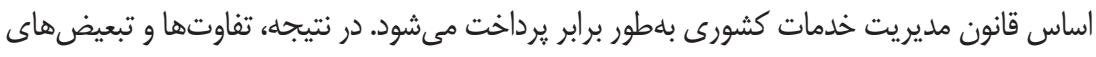
موجود، با وجود تمهيدات قانونى لازم در بخش مزايا و فرصتهاى رشد و ترقى و كسب شايستكى هاى فردى و حرفهاى به تكرار خرخه اشارهشده كمك مىنمايد. حاكميت مردخويى علاوه بر نارضايتى در

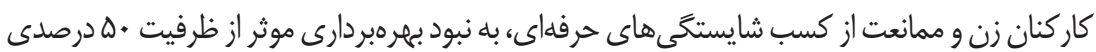
نيروى كار زنان جامعه در راستاى توسعه كشور منجر مى كردد.

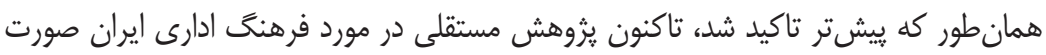
نيذيرفت، از اينرو يزوهش حاضر كه به سنجش فرهنگ ادارى با رويكردى نهادى مى يردازد، نخستين

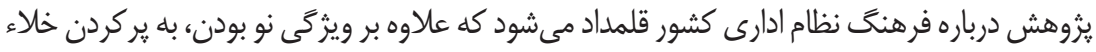


دادههاى سطح نهادى در حوزههاى فرهنگىى، ادارى، و مديريتى در سطح ملّى و سازمانى مى يردازد و

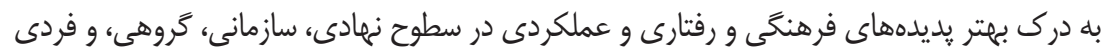

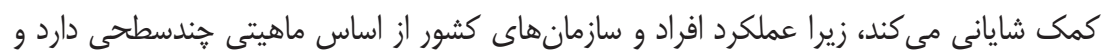
فقدان اطلاعات نهادى يكى از خالشهاى بيشاروى اينَّونه تحليلهاست.

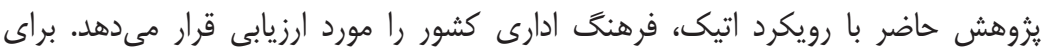

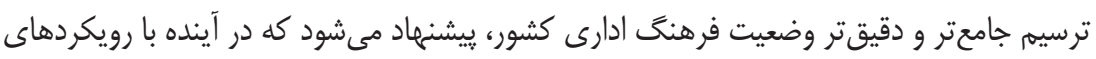

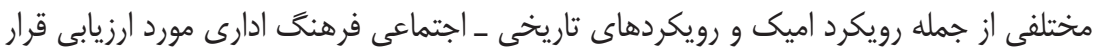

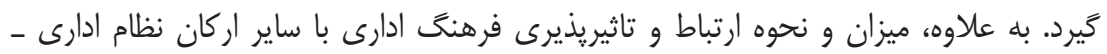

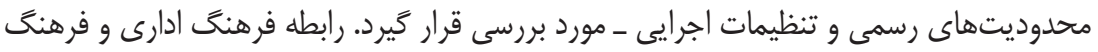

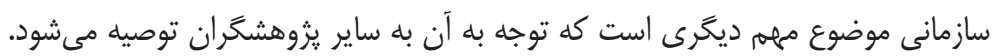
نتايج اين يزوهش بلهور مستقيم مىتواند به عنوان بخشى از دادههاى راهبردى به به بهان

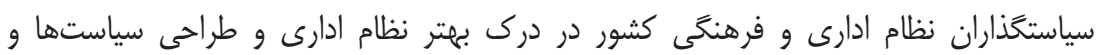

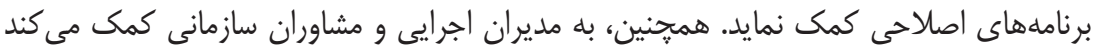
كه در طراحى تصميمهاى راهبردى و برنامههاى توسعه سازمانى، نقش ساختار فرهنكى نظام ادارى كشور و محدوديتها و فرصتهاى آن را مورد توجه قرار دهند دهن. 


\section{منابع}

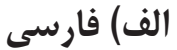

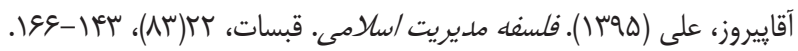

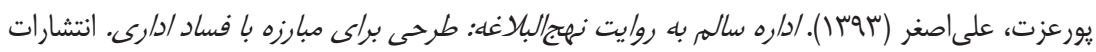

$$
\begin{aligned}
& \text { بنياد نهجالبلاغه. } \\
& \text { يورعزت، علىاصغر (هوج"). اسوهيردازى از حكومت حقمدار براى آيندكان. بُزوهشهاى نهجالبلاغه، } \\
& \text {. } 11-9 \text { ، (1) (1) } 10
\end{aligned}
$$

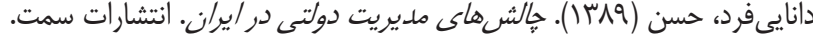

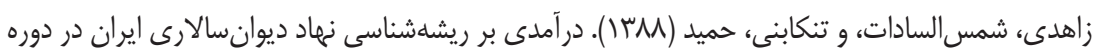

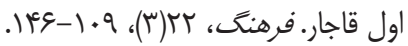

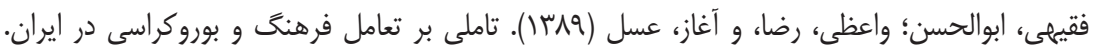

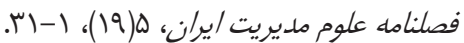

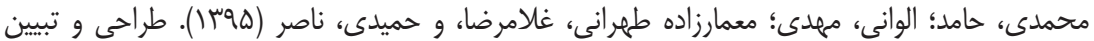

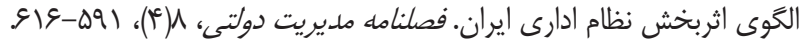

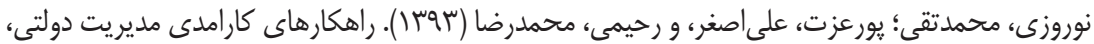

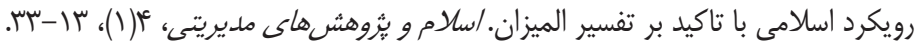

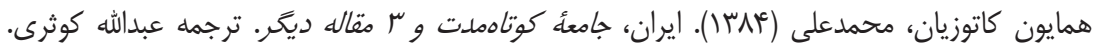

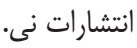

Al-Helal, H. U. M. (2014). Administrative Culture. A Comparative Analysis between Bangladesh and USA. University of Dhaka.

Almond, G. A., \& Verba, S. (1963). The Civic Culture. Political Attitudes and Democracy in Five Nations. Princeton University Press.

Aoki, M., Kuran, T., \& Roland, G. (2012). Institutions and Comparative Economic Development (Vol. 150). Palgrave Macmillan.

Boettke, P. J., \& Coyne, C. J. (2009). Context Matters: Institutions and Entrepreneurship (Vol. 22). Now Publishers Inc.

Daniel, S. J., Cieslewicz, J. K., \& Pourjalali, H. (2012). The Impact of National Economic Culture and Country-Level Institutional Environment on Corporate Governance Practices. Management International Review, 52(3), 365-394.

Divedi, O., \& Gow, J. (1999). From Bureaucracy to Public Management: The Administrative Culture of Canada Peterborough, ONT. Broadview Press. 
Dwivedi, O.-P. (2005). Administrative Culture and Values: Approaches. Administrative Culture in a Global Context, 19-36. de Sitter Publications.

Farazmand, A. (2001). State Tradition and Public Administration in Iran: Ancient and Contemporary Perspectives. Public Administration and Public Policy, 94(1), 535-550.

Garrido, E., Gomez, J., Maicas, J. P., \& Orcos, R. (2014). The Institution-Based View of Strategy: How to Measure It. Business Research Quarterly, 17(2), 82-101.

Goldschmidt, N., Zweynert, J., Nerré, B., \& Schuß, H. (2006). Culture and Economics. Intereconomics, 41(4), 176-199.

Hatch, M. J. (1993). The Dynamics of Organizational Culture. Academy of Management Review, 18(4), 657-693.

Helmke, G., \& Levitsky, S. (2004). Informal Institutions and Comparative Politics: A Research Agenda. Perspectives on Politics, 2(4), 725-740.

Henderson, K. M. (2004). Characterizing American Public Administration. International Journal of Public Sector Management, 17(3), 234-250.

Hofstede, G. (1980). Values and Culture. Culture's Consequences: International Differences in Work-Related Values. Sage Publications.

Hofstede, G. H., Hofstede, G. J., \& Minkov, M. (2010). Cultures and Organizations: Software of the Mind (Vol. 3): Mcgraw-hill New York.

House, R. J., Hanges, P. J., Javidan, M., Dorfman, P. W., \& Gupta, V. (2004). Culture, Leadership, and Organizations: The GLOBE Study of 62 Societies: Sage Publications.

Howlett, M. (2002). Understanding National Administrative Cultures and Their Role in Administrative Reform: A Neo-Institutional Model of Administrative Styles. International Association of Schools and Institutes of Public Administration. Section V: Accountability, Culture and Trust. Istanbul, 6-7.

Jabbra, J. G., \& Dwivedi, O. (2004). Globalization, Governance, and Administrative Culture. International Journal of Public Administration, 27(13-14), 1101-1127.

Jamil, I. (1994). Administrative Culture: A Mode of Understanding Public Administration across Cultures. Research in Urban Policy, 5(5), 275-294.

Jamil, I. (2002). Administrative Culture in Bangladesh: Tensions between Tradition and Modernity. International Review of Sociology/Revue Internationale de Sociologie, 12(1), 93-125.

Jamil, I. (2007). Administrative Culture in Bangladesh: AH Development Pub. House in Association with Centre for Development Governance.

Jamil, I., \& Dangal, R. (2009). The State of Bureaucratic Representativeness and Administrative Culture in Nepal. Contemporary South Asia, 17(2), 193-211. 
Jamil, I., Askvik, S., \& Hossain, F. (2013). Introduction to the Special Issue on Administrative Culture in Developing and Transitional Countries. International Journal of Public Administration, 36(13), 897-899.

Jreisat, J. E. (2019). Organizational Perspective in Comparative and Development Administration. In A. Farazmand (Ed.), Handbook of Comparative and Development Public Administration: Second Edition, Revised and Expanded: Marcel Dekker, Inc.

Kuruvilla, P. (1973). Administrative Culture in Canada: Some Perspectives. Canadian Public Administration, 16(2), 284-297.

Lam, J. T. (1994). Administrative Culture and Democracy in Hong Kong. Asian Affairs: An American Review, 21(3), 166-181.

North, D. (1990). Institutions, Institutional Change and Economic Performance Cambridge University Press. New York.

Park, S.-M. (2012). How to Measure Informal Institutions. Philipps-Universität Marburg.

Pečarić, M. (2011). Administrative Culture. Hrvatska i komparativna javna uprava: časopis za teoriju i praksu javne uprave, 11(2), 379-409.

Randolph, G. M., \& Rivero, M. (2017). Informal Institutions, Public Policy, and Entrepreneurship Public Policy, Productive and Unproductive Entrepreneurship. Edward Elgar Publishing.

Sautet, F. (2005). The Role of Institutions in Entrepreneurship: Implications for Development Policy. Mercatus Policy Primer (1).

Schwartz, S. H. (1992). Universals in the Content and Structure of Values: Theoretical Advances and Empirical Tests in 20 Countries. Advances in Experimental Social Psychology, 25(1), 1-65. 